\title{
Comparative Study between Pressure Controlled Ventilation and Volume Controlled Ventilation and Their Effects on Respiratory Mechanics for Posterior Lumbar Spine Surgery Patients in Prone Position
}

Ahmed Mohamed Reda Ragheb*1, Ahmed ELSaied Abdul Rahman², Ayman Mohamady Aldemrdash ${ }^{1}$, Sherif Kamal Hafez Arafa ${ }^{1}$

${ }^{1}$ Department of Anesthesiology and Intensive Care, Faculty of Medicine, Aswan University, ${ }^{2}$ Department of Anesthesiology and Intensive Care, Faculty of Medicine, Sohag University, Egypt

*Corresponding author: Ahmed Mohamed Reda Ragheb, Mobile: (+20)1006228286, E-Mail: dr_ahmedmorsi@ yahoo.com

\begin{abstract}
Background: Prone position is one of the challenging and widely used surgical positions with high rates of complications. The applied position and selected ventilation parameters during the operation are known to influence the pulmonary mechanics.

Objective: This study was conducted to compare two modes of ventilation; volume controlled and pressurecontrolled ventilation and their effect on improvement of respiratory dynamics.

Patients and Methods: This prospective randomized controlled study included a total of 60 patients who had posterior lumbar spine surgery in prone position, attending at Department of Anesthesiology and Surgical ICU, Aswan University Hospital, Egypt. This study was conducted between June 1, 2017 to December 13, 2018. Patients were randomly divided between two groups, 30 patients each; Group (I): were received VCV mode and Group (II): were received PCV mode. Then study parameters were recorded intraoperative and postoperative in the two groups of ventilation modes. The study parameters which were recorded: Peak inspiratory pressure $\left(\mathrm{P}_{\text {peak }}\right)$, Plateau pressure $\left(\mathrm{P}_{\text {plateau }}\right)$, dynamic compliance $\left(\mathrm{C}_{\mathrm{dyn}}\right)$, ETCO2, Tidal volume $\left(\mathrm{V}_{\mathrm{T}}\right)$, respiratory rate $(\mathrm{RR})$.

Results: As regarding $\mathrm{P}_{\text {peak }}$ and $\mathrm{P}_{\text {plat }}$, they were statistically significant lower in PCV group than VCV group at both supine and prone positions. As regarding $\mathrm{C}_{\mathrm{dyn}}$, it was statistically significant higher in PCV group than VCV group at both supine and prone positions. Arterial oxygen tension $\left(\mathrm{PaO}_{2}\right)$ was significantly higher in PCV group intraoperative in prone position and postoperative.

Conclusions: Compared with VCV, PCV is better regarding the respiratory dynamics including lower $\mathrm{P}_{\text {peak }}$ and $\mathrm{P}_{\text {plat. }}$ It has also higher $\mathrm{C}_{\mathrm{dyn}}$ and oxygenation. $\mathrm{PCV}$ it is more suitable for general anesthesia of posterior lumbar spine surgery patients in prone position.
\end{abstract}

Keywords: pressure-controlled ventilation, volume controlled ventilation, respiratory mechanics, lumbar spine surgery.

\section{INTRODUCTION}

The number of lumbar spine surgical procedures has been obviously increasing (1). The most important indications for spine surgery include intervertebral disc prolapse, degenerative disc disease, scoliosis and spondylolisthesis. This type of patients are a prominent group among hospitalized patients especially most of them present with acute surgical condition. In these surgeries, perioperative complications mostly occur in about $22 \%$ of patients. Among complications, those affecting the respiratory system which have been of high morbidity rates ${ }^{(2)}$.

During posterior lumbar spine surgery, the prone position is commonly used to expose the dorsal surface of the body for specific surgical indications (3). During general anaesthesia, changing from the supine to prone position may have adverse effects on epidural venous pressure and respiratory mechanics (4). For surgeons, the major problems encountered in performing spine surgery are exposure of the surgical field and bleeding from it. For anaesthetist, the major problems noted in those patients are difficulties in the

ventilation and cardiac dysfunction during prone position. The prone position alters respiratory dynamics by increasing airway pressure and decreasing respiratory compliance. The applied positioning and selected ventilation parameters during the operation are known to influence the pulmonary mechanics and so oxygenation ${ }^{(5)}$.

In volume controlled ventilation (VCV) mode, tidal volume, respiratory rate and Inspiration/ expiration (I/E) are under control of the anaesthetist. The aim of this mode is to perform fixed minute ventilation for the patient. The airway pressure in VCV mode may change depending to resistance and compliance therefore there is a risk of increased airway pressures. For this reason, pulmonary compliance and airway resistance should be monitored ${ }^{(6)}$.

In pressure controlled ventilation (PCV), the parameters that are under anaesthetist control are peak airway inspiration pressure, respiratory rate and Inspiration / expiration (I/E) ratio. Peak flow rate is 
reached in the beginning of inspiration. It decreases throughout the inspiration and continues until the end of inspiration time. In PCV mode, attention should be paid to tidal volume which may change ${ }^{(7)}$.

This study was designed to compare between two modes of ventilation, pressure controlled ventilation and volume controlled ventilation regarding respiratory dynamics including peak pressure, plateau pressure and dynamic compliance to distinguish which of them is better in improving the perioperative pulmonary effects and oxygenation for patients of posterior lumbar spine surgeries in prone position. This because all the previously mentioned respiratory parameters are changing during this type of patients which were reflecting on respiratory mechanics, oxygenation, and morbidities.

\section{PATIENTS AND METHODS}

This prospective randomized controlled study included a total of 60 patients who had posterior lumbar spine surgery in prone position, attending at Department of Anesthesiology and Surgical ICU, Aswan University Hospital, Egypt. This study was conducted between June 1, 2017 to December 13, 2018.

\section{Ethical Consideration:}

This study was ethically approved by Ethical Committee, Faculty of Medicine, Aswan University Hospital. Written informed consent from every participant in this research was taken. The confidentiality of all participants admitted to this study was fully protected. Ethical aspects whether substantial or procedural were implicated in this study. The signed informed consent form was a permanent part of the participant's study records and will be maintained in the same manner as other records.

Patients were randomly selected by opening sealed envelopes, to receive either PCV or VCV. Computerized randomization was done to divide the 60 patients of the study into two groups, 30 patients each; Group (I): were received VCV mode and Group (II): were received PCV mode.

\section{Inclusion criteria:}

- Age: 20:60 years old.

- Gender: males and females.

- BMI 18.5: $29.9 \mathrm{Kg} / \mathrm{m} 2$.

- Non-smoker.

- Free from cardiac, pulmonary, hepatic, renal, endocrine, cerebrovascular or neuromuscular diseases.

- No history of previous lung surgery.

- Expected surgery time is 2 hours.

- No expected massive intra-operative bleeding.

- Fulfill the ethical considerations.

\section{Exclusion criteria:}

- Age $<20$ years or $>60$ years old.

- Body mass index (BMI) equal or more than 30 $\mathrm{kg} / \mathrm{m} 2$.
- ASA III \& IV.

- Smoker.

- Cardiac or pulmonary or hepatic or renal or endocrine or cerebrovascular or neuromuscular diseases.

- Previous lung surgery.

- Expected surgery time more than 2 hours.

- Expected massive intra-operative bleeding.

- Didn't fulfill the ethical considerations.

All the basic preoperative laboratory and radiological investigations were done for all patients to confirm that all patients fulfilled the inclusion and exclusion criteria.

24 hours preoperatively, arterial blood gases $(\mathrm{ABG})$ in the form of $\mathrm{PH}, \mathrm{PaO} 2, \mathrm{PaCO} 2, \mathrm{HCO} 3$ were checked and recorded to evaluate the basic normal levels for the patient, so we could compare between these basic levels and the recorded intraoperative and postoperative results in the two groups of ventilation modes through the study.

Preoperatively, all the patients were planned to fast 7 hours and a peripheral intravenous line 18 gauge was established in the ward with premedication of ranitidine $50 \mathrm{mg}$ and odansetron 4 $\mathrm{mg}$ intravenous medications were given one hour before surgery.

On arrival to the operating room, standard monitoring were applied consisting of ECG, pulse oximetry, non-invasive blood pressure (which setted to measure the blood pressure every 5 minutes).

After Allen's test was satisfactory, an arterial cannula was inserted in the radial artery after induction of anaesthesia for extraction of $\mathrm{ABG}$ samples. The anaesthesia machine and the monitor used in the study were the same in all patients of the study. The monitor was equipped by anaesthetic gas and $\mathrm{CO} 2$ analyser (capnography).

All given medications doses and ventilator settings in the study were calculated according to the ideal body weight equation:

- For males: $50+0.91$ (height in $\mathrm{cm}-152.4$ )

- For females: $45.5+0.91$ (height in cm - 152.4)

Preoxygenation for 5 minutes was done in all patients with $\mathrm{FiO} 2$ of $100 \%$ followed by induction which was established for all patients also and done in supine position by IV injection of morphine 0.1 $\mathrm{mg} / \mathrm{kg}$, Lidocaine (2\%) $0.03 \mathrm{mg} / \mathrm{kg}$ before propofol injection, Propofol $2 \mathrm{mg} / \mathrm{kg}$ and muscle relaxation by atracurium $0.5 \mathrm{mg} / \mathrm{kg}$.

Maintenance of anesthesia were established the same also for all patients by isoflurane with end tidal concentration of $0.8: 1.2$. Atracurium $0.1 \mathrm{mg} / \mathrm{kg}$ IV was given every 20 minutes from induction dose time. IV fluid replacement by crystalloids was calculated according to the fasting time and intraoperative fluid losses. Ketorolac $60 \mathrm{mg}$ IV with $150 \mathrm{ml}$ normal saline IV infusion over 1 hour and 
paracetamol $1 \mathrm{gm} \mathrm{IV}$ infusion were given as a part of analgesia for all patients of the study.

Volume controlled ventilation (VCV) group ventilator settings were adjusted as tidal volume (VT) $8 \mathrm{ml} / \mathrm{kg}$, RR was adjusted to maintain an end tidal CO2 (ETCO2) of $33: 35 \mathrm{mmHg}$, Inspiratory to expiratory time (I : E) of $1: 2$, Positive end expiratory pressure (PEEP) of $0 \mathrm{~cm} \mathrm{H} 2 \mathrm{O}$ and $\mathrm{FiO} 250 \%$ (O2 : air concentration $=1: 1$ ).

Pressure controlled ventilation (PCV) group ventilator settings were adjusted as Inspiratory pressure was setted in two times; after induction of anaesthesia in supine position and once the patient in prone position. At both times the $\mathrm{P}_{\text {ins }}$ was setted to deliver a tidal volume (VT) of $8 \mathrm{ml} / \mathrm{kg}$, RR was adjusted to maintain an end tidal $\mathrm{CO} 2$ (ETCO2) of $33: 35 \mathrm{mmHg}$, Inspiratory to expiratory time (I : E) ratio of $1: 2$, Positive end expiratory pressure (PEEP) of $0 \mathrm{~cm} \mathrm{H} 2 \mathrm{O}, \mathrm{FiO} 250 \%(\mathrm{O} 2:$ air concentration $=1$ $: 1)$.

Recovery from anesthesia at the end of the surgery done by stoppage of isoflurane, neostigmine 0.04 $\mathrm{mg} / \mathrm{kg}$, atropine $0.02 \mathrm{mg} / \mathrm{kg}$.

After induction of anesthesia and in supine position, the following parameters were recorded:

- Peak inspiratory pressure $\left(\mathrm{P}_{\text {peak }}\right)$.

- Plateau pressure ( $\left.\mathrm{P}_{\text {plateau }}\right)$.

- Dynamic compliance $\left(\mathrm{C}_{\mathrm{dyn}}\right)$ be this equation:

$$
C_{d y n}=\frac{V_{T}}{\text { PIP }- \text { PEEP }}
$$

- End tidal Carbon dioxide (ETCO2).

- Tidal volume $\left(\mathrm{V}_{\mathrm{T}}\right)$.

- Respiratory rate (RR).

30 minutes after prone position, these parameters were recorded:

- $P_{\text {peak }}$
- $\mathrm{P}_{\text {plateau }}$

- $\mathrm{C}_{\text {dyn }}$ by the same equation

- ETCO2

- $\mathrm{V}_{\mathrm{T}}$

- RR

- Arterial blood gases for documentation of $\mathrm{PH}, \mathrm{PaO} 2$ and $\mathrm{PaCO} 2$.

One hour postoperatively in the recovery room, these parameters were recorded:

- Arterial blood gases for documentation of $\mathrm{PH}, \mathrm{PaO} 2$ and $\mathrm{PaCO} 2$.

\section{Statistical methods}

Descriptive analysis was presented using the mean values and standard deviations (SD). The compliances of the variables with the normal distribution were analysed. As the continuous variables were not complaint with the normal distribution, Wilcoxon signed ranks test was used for comparison of dependent variables, while MannWhitney $U$ test was used for comparison of independent variables. The Student t test was used for independent continuous variables with normal distribution, while paired samples t test was used for the comparison of dependent variables with normal distribution. The results of the evaluation were considered to be statistically significant when $\mathrm{p}$ values were less than 0.05 .

\section{RESULTS}

Comparison between the two groups of ventilation group (I) and group (II) was done in these points: ETCO2 in supine position. ETCO2 in prone position. VT in supine position. VT in prone position. $\mathrm{RR}$ in supine position. $\mathrm{RR}$ in prone position. $\mathrm{P}_{\text {Peak }}$ in supine position. $\mathrm{P}_{\text {Peak }}$ in prone position. $\mathrm{P}_{\text {Plat }}$ in supine position. $\mathrm{P}_{\text {Plat }}$ in prone position. $\mathrm{C}_{\mathrm{dyn}}$ in supine position. $\mathrm{C}_{\mathrm{dyn}}$ in prone position.

Table (1): Respiratory parameters during mechanical ventilation.

\begin{tabular}{|l|l|l|l|l|}
\hline \multicolumn{2}{|l|}{ Item } & $\begin{array}{l}\text { VCV Group } \\
(\mathbf{n = 3 0 )}\end{array}$ & $\begin{array}{l}\text { PCV Group } \\
(\mathbf{n = 3 0 )}\end{array}$ & P-value \\
\hline \multirow{2}{*}{ ETCO2 } & Supine & $34.1 \pm 1.2$ & $34.4 \pm 1.0$ & 0.238 \\
\cline { 2 - 5 } & Prone & $35.0 \pm 1.1$ & $34.2 \pm 1.0$ & 0.006 \\
\hline \multirow{2}{*}{$\mathbf{V}_{\mathbf{T}}$} & Supine & $525.7 \pm 35.0$ & $504.0 \pm 51.1$ & 0.061 \\
\cline { 2 - 5 } & Prone & $522.0 \pm 33.0$ & $443.0 \pm 39.8$ & $0.000^{*}$ \\
\hline \multirow{2}{*}{$\mathbf{R R}$} & Supine & $12.1 \pm 1.1$ & $11.3 \pm 0.99$ & $0.004^{*}$ \\
\cline { 2 - 5 } $\mathbf{P}_{\text {peak }}$ & Prone & $10.1 \pm 0.97$ & $11.0 \pm 0.98$ & $0.001^{*}$ \\
\hline \multirow{2}{*}{$\mathbf{P}_{\text {plat }}$} & Supine & $20.1 \pm 1.2$ & $18.5 \pm 1.0$ & $0.000^{*}$ \\
\cline { 2 - 5 } & Prone & $21.8 \pm 0.4$ & $20.3 \pm 0.7$ & $0.000^{*}$ \\
\hline \multirow{2}{*}{$\mathbf{C}_{\text {dyn }}$} & Supine & $19.2 \pm 0.99$ & $17.1 \pm 0.8$ & $0.000^{*}$ \\
\cline { 2 - 5 } & Prone & $19.9 \pm 0.8$ & $18.5 \pm 0.7$ & $0.000^{*}$ \\
\cline { 2 - 5 } & Supine & $39.8 \pm 4.1$ & $43.0 \pm 3.1$ & $0.001^{*}$ \\
\hline
\end{tabular}

N.B: Parameters in supine position were recorded in supine position after induction and before turning the patient to prone position, while parameters in prone position were recorded after 30 minutes from putting the patient in prone position.

As regarding $\mathrm{V}_{\mathrm{T}}$, it was statistically significant lower in PCV group than VCV group in prone position $(\mathrm{P}=0.000)$, while there was no significant difference between the two studied groups in supine

position. As regarding $\mathrm{ETCO} 2$ there was no significant difference between the two studied groups in supine or prone positions. As regarding $\mathrm{RR}$, it was statistically significant lower in PCV 
group than VCV group in supine \& prone positions $\left(\mathrm{P}=0.004\right.$ and 0.001 , respectively). As regarding $\mathrm{P}_{\text {peak }}$ and $\mathrm{P}_{\text {plat }}$, they were statistically significant lower in PCV group than VCV group in supine and prone positions $\left(\mathrm{P}=0.000\right.$, all). As regarding $\mathrm{C}_{\mathrm{dyn}}$, it was statistically significant higher in PCV group than $\mathrm{VCV}$ group in supine and prone positions $(\mathrm{P}=0.001$ and 0.000 , respectively), as shown in (Table 1).

Comparison between respiratory parameters in supine and prone positions was done in the following points: $P_{\text {Peak }}$ in VCV group. $P_{\text {Peak }}$ in PCV group. $P_{\text {Plat }}$ in VCV group. $\mathrm{P}_{\text {Plat }}$ in PCV group. $\mathrm{C}_{\mathrm{dyn}}$ in $\mathrm{VCV}$ group. $\mathrm{C}_{\mathrm{dyn}}$ in $\mathrm{PCV}$ group.
With parameters in supine position were recorded in supine position after induction and before putting the patient in prone position, while parameters in prone position were recorded after 30 minutes from putting the patient in prone position. $\mathrm{P}_{\text {peak }}$ in supine position was statistically significant lower than in prone position in VCV group and in PCV ( $\mathrm{P}=0.000$, both). $\mathrm{P}_{\text {plat }}$ in supine position was statistically significant lower than in prone position in both VCV group and in PCV $(\mathrm{P}=0.001$ and 0.000 , respectively). $\mathrm{C}_{\mathrm{dyn}}$ in supine position was statistically significant higher than in prone position in VCV group and in $\mathrm{PCV}(\mathrm{P}=0.000$, both). That is shown in (Table 2).

Table (2): Respiratory parameters during mechanical ventilation according to patient position.

\begin{tabular}{|c|l|l|l|l|}
\hline \multirow{2}{*}{ Item } & $\begin{array}{l}\text { Supine } \\
(\mathbf{n = 3 0 )}\end{array}$ & $\begin{array}{l}\text { Prone } \\
(\mathbf{n = 3 0})\end{array}$ & P-value \\
\hline \multirow{2}{*}{$\mathbf{P}_{\text {peak }}$} & VCV & $20.1 \pm 1.2$ & $21.8 \pm 0.41$ & $0.000^{*}$ \\
\cline { 2 - 5 } & PCV & $18.5 \pm 1.04$ & $20.3 \pm 0.75$ & $0.000^{*}$ \\
\hline \multirow{2}{*}{$\mathbf{P}_{\text {plat }}$} & VCV & $19.2 \pm 1.0$ & $19.9 \pm 0.8$ & $0.001^{*}$ \\
\cline { 2 - 5 } & PCV & $17.1 \pm 0.76$ & $18.5 \pm 0.7$ & $0.000^{*}$ \\
\cline { 2 - 5 } $\mathbf{C}_{\text {dyn }}$ & VCV & $39.8 \pm 4.1$ & $30.8 \pm 3.7$ & $0.000^{*}$ \\
\cline { 2 - 5 } & PCV & $43.0 \pm 3.1$ & $38.6 \pm 3.1$ & $0.000^{*}$ \\
\hline
\end{tabular}

As regarding demographic data there was no significant difference between the two studied groups as shown in (Table 3).

Table (3): Demographic data.

\begin{tabular}{|l|l|l|l|c|}
\hline \multicolumn{2}{|l|}{ Item } & $\begin{array}{l}\text { VCV Group } \\
(\mathbf{n = 3 0})\end{array}$ & $\begin{array}{l}\text { PCV Group } \\
(\mathbf{n = 3 0})\end{array}$ & P-value \\
\hline \multicolumn{2}{|l|}{ Age (years) } & $33.03 \pm 10.0$ & $31.3 \pm 9.3$ & 0.489 \\
\hline \multirow{2}{*}{ Gender } & Male & $25(83.3 \%)$ & $21(70 \%)$ & \multirow{2}{*}{0.222} \\
\cline { 2 - 4 } & Female & $5(16.7 \%)$ & $9(30 \%)$ & 0.218 \\
\hline \multicolumn{2}{|l|}{ BMI (kg/m2) } & $25.4 \pm 1.9$ & $24.3 \pm 4.2$ & \\
\hline
\end{tabular}

Comparison between the two groups of ventilation group (I) and group (II) was done in: ABG preoperatively. $\mathrm{ABG}$ intraoperatively in prone position. $\mathrm{ABG}$ postoperatively.

With preoperative parameters were recorded 24 hours preoperative, parameters in supine position were recorded in supine position after induction and before putting the patient in prone position, while parameters in prone position were recorded after 30 minutes from putting the patient in prone position. As regarding Perioperative arterial blood gas analysis, Pao2 was statistically significant higher in PCV group than VCV group intraoperatively in prone position and postoperatively $(\mathrm{P}=0.002$ and 0.000 respectively). But there was no significant difference between the two studied groups regarding $\mathrm{PH}$ or $\mathrm{PaCo} 2$ as shown in (Table 4). 
Table (4): Arterial blood gas analysis of the studied groups.

\begin{tabular}{|l|l|l|l|l|}
\hline \multicolumn{2}{|c|}{ Item } & $\begin{array}{l}\text { VCV Group } \\
(\mathbf{n = 3 0})\end{array}$ & $\begin{array}{l}\text { PCV Group } \\
(\mathbf{n = 3 0 )}\end{array}$ & P-value \\
\hline \multirow{3}{*}{$\mathbf{P H}$} & Preoperative & $7.38 \pm 0.03$ & $7.38 \pm 0.02$ & 0.681 \\
\cline { 2 - 5 } & Prone & $7.36 \pm 0.03$ & $7.338 \pm 0.03$ & 0.092 \\
\cline { 2 - 5 } & Postoperative & $7.39 \pm 0.03$ & $7.39 \pm 0.02$ & 0.761 \\
\hline \multirow{3}{*}{ Pao2 } & Preoperative & $82.3 \pm 3.6$ & $82.1 \pm 4.03$ & 0.808 \\
\cline { 2 - 5 } & Prone & $150.7 \pm 21.5$ & $166.8 \pm 17.4$ & $0.002^{*}$ \\
\cline { 2 - 5 } & Postoperative & $82.2 \pm 3.4$ & $90.1 \pm 3.6$ & $0.000^{*}$ \\
\hline \multirow{3}{*}{ PaCo2 } & Preoperative & $38.8 \pm 3.3$ & $37.9 \pm 2.5$ & 0.226 \\
\cline { 2 - 5 } & Prone & $36.1 \pm 1.9$ & $35.4 \pm 2.6$ & 0.221 \\
\cline { 2 - 5 } & Postoperative & $38.4 \pm 1.9$ & $38.6 \pm 1.8$ & 0.647 \\
\hline
\end{tabular}

\section{DISCUSSION}

The results of the current study indicated that, in patients undergoing posterior lumbar spine surgery in the prone position when the patient was anesthetised and turned from supine to prone position, airway pressure increased including peak airway pressure $\left(\mathrm{P}_{\text {Peak }}\right)$ and plateau pressure $\left(\mathrm{P}_{\text {Plat }}\right)$ in both groups. The increase in airway pressure resulted in decrease in the dynamic compliance $\left(\mathrm{C}_{\mathrm{dyn}}\right)$ in both groups also.

Pressure controlled ventilation provided lower airway pressures and higher compliance compared with volume controlled ventilation when the ventilator was setted to deliver the same tidal volume $(8 \mathrm{ml} / \mathrm{Kg})$ and to maintain a constant end tidal $\mathrm{CO} 2$ of $(33-35 \mathrm{mmHg})$ in both modes.

This improvement of Cdyn was reflected on intraoperative and postoperative oxygenation for these patients. Intraoperative and postoperative oxygenation both were significantly higher in PCV group (group II). Oxygenation which was higher in PCV was recorded intraoperatively in prone position and one hour postoperatively in the recovery room, which is appropriate for this type of surgeries. So pressure controlled ventilation mode might be more appropriate for general anaesthesia in prone position especially in posterior lumbar spine surgeries.

Comparing the two modes of ventilation in our study we considered keeping the targeted $\mathrm{V}_{\mathrm{T}}$, ETCO2 (through controlling the respiratory rate) and PEEP constant in both groups to increase the accuracy of results as these parameters are affecting airway pressure and dynamic compliance which are the primary outcome of the study. We targeted a constant $\mathrm{V}_{\mathrm{T}}$ of $(8 \mathrm{ml} / \mathrm{Kg})$ in both groups, constant ETCO2 of (33-35 mmHg) by controlling the RR and constant PEEP of 0 (zero).

Patients with a BMI $>30 \mathrm{~kg} / \mathrm{m} 2$ were excluded from this study to avoid additional confounding factors because obesity may alter pulmonary mechanics during prone position. A previous study demonstrated that, when patients were prone positioned on the Wilson frame, the $\mathrm{P}_{\text {peak }}$ in the obese group (BMI $<32 \mathrm{~kg} / \mathrm{m} 2)$ was significantly higher than that in the normal group $(\mathrm{BMI}>27 \mathrm{~kg} / \mathrm{m} 2)$ in the supine and prone positions during VCV ${ }^{(8)}$. The result of this study does not extend to obese patients, and further study is needed to elucidate the difference between VCV and PCV with regard to pulmonary mechanics in obese patients.

As regarding the constant parameters of ventilation in the two studied groups: $V_{T}$ was statistically significant lower in PCV group than $\mathrm{VCV}$ group in prone position, while there was no significant difference between the two studied groups in supine position. ETCO2 there was no significant difference between the two studied groups in supine or prone positions and as regarding RR (which used to control the ETCO2) was statistically significant lower in PCV group than VCV group in supine and prone positions. And these results confirm that these parameters were fixed during the comparison between the two modes of ventilation, in other words, fixed $\mathrm{VT}$ of $8 \mathrm{ml} / \mathrm{Kg}$ and ETCO2 of 33-25 mmHg.

As regarding the respiratory dynamics: $\mathrm{P}_{\text {peak }}$ in prone position was statistically significant higher than in prone position in both groups, VCV group and PCV group. $P_{\text {peak }}$ was statistically significant lower in PCV group than VCV group in both supine and prone position. $\mathrm{P}_{\text {plat }}$ in prone position was statistically significant higher than in supine position in both groups, VCV group and PCV group. $P_{\text {plat }}$ was statistically significant lower in PCV group than VCV group in both supine and prone positions. $\mathrm{C}_{\mathrm{dyn}}$ in prone position was statistically significant lower than in prone position in both groups, VCV group and $\mathrm{PCV}$ group. $\mathrm{C}_{\mathrm{dyn}}$ was statistically significant higher in PCV group than VCV group in supine and prone positions.

And these results confirm that PCV is a better mode than VCV for respiratory dynamics of this type of patients which decreases also the incidence of intraoperative and postoperative atelectasis and improves ventilation. 
As regarding oxygenation: As regarding Perioperative arterial blood gas analysis, $\mathrm{PaO} 2$ was statistically significant higher in PCV group than VCV group, intraoperatively in prone position and postoperatively. But there was no significant difference between the two studied groups regarding $\mathrm{PH}$ or $\mathrm{PaCO} 2$.

And these results reflect that PCV is a better mode than VCV for respiratory dynamics of this type of patients which improved intraoperative and postoperative oxygenation due to improved ventilation. In a study conducted by Krayer $\boldsymbol{e t}$ al. ${ }^{(9)}$ where they used computed tomography (CT), they demonstrated that the end-expiratory position of the diaphragm did not change in patients with supine position after the induction of anaesthesia and relaxation of muscles, whereas there was a significant upwards volume shift in prone position. The movement patterns of the diaphragm during mechanical inflation in supine position are uniform, while most movements in prone position are in the dorsal region. As a result $\mathrm{P}_{\text {Peak }}$ and $\mathrm{P}_{\text {Plat }}$ increased and Cdyn decreased after patient turned to prone position (9). Similarly, in the current study, $\mathrm{P}_{\text {peak }}$ and $\mathrm{P}_{\text {plat }}$ values increased and dynamic compliance values declined in both groups of ventilation after prone position.

Jo et al. ${ }^{(10)}$ found lower $\mathrm{P}_{\text {peak }}$ levels during PCV in both supine and prone positions when compared with VCV. Kim et al. ${ }^{(8)}$ compared the PCV and VCV modes during prone position in highlevel spinal cord injury patients and found that $\mathrm{P}_{\text {peak }}$ increased after prone positioning in both groups, but this increase was significantly higher in VCV group compared with PCV group, results in those studies are the same with our results in this study.

Major finding of the present study is PCV mode was associated with lower $\mathrm{P}_{\text {peak }}$ and $\mathrm{P}_{\text {plateau }}$ levels during both supine and prone positions. Licker et al. ${ }^{(11)}$ and Oeckler et al. ${ }^{(12)}$ have been showed that elevated respiratory pressures could lead to acute lung injury (ALI), and also minimal increases in $\mathrm{P}_{\text {peak }}$ can result in postoperative ALI risk ${ }^{(13)}$. Boussarsar et al. ${ }^{(14)}$ reported that $P_{\text {plateau }}$ lower than $35 \mathrm{cmH} 20$ was associated with lower incidence of death and barotrauma in surgical cases under general anaesthesia.

Palmon et al. $^{(15)}$ have reported an $18 \%$ decrease in $C_{d y n}$ when patients were turned to the prone position on the Wilson frame during VCV. This is consistent with the results of our study, in which the $\mathrm{C}_{\text {dyn }}$ decreased in the VCV group after prone positioning. The $\mathrm{C}_{\mathrm{dyn}}$ in the PCV group was significantly higher compared with the VCV group during both supine and prone positions. These results are contrary to those of a recent study in which Choi et al. ${ }^{(16)}$ reported that PCV did not improve $\mathrm{C}_{\mathrm{dyn}}$ during one lung ventilation in the prone position.
Pelosi et al. ${ }^{(17)}$ studied the effects of prone positioning on respiratory mechanics in 17 patients operated for disc herniation and reported that there was no change in the compliance of the lungs, chest wall, and respiratory system. We observed that compliance decreased in both groups of PCV and $\mathrm{VCV}$ in prone position contrary to the findings of Pelosi et al.

Wahba et al. $^{(18)}$ found that oxygenation improved, $\mathrm{PaCO} 2$ values did not change, and $\mathrm{EtCO} 2$ values decreased in prone position in their study where they performed elective lumbar decompression surgery for 20 patients of ASA I-II. The researchers concluded that this result was associated with the increased excretion of $\mathrm{CO} 2$ due to elevated tidal volume caused by increased flexibility of the chest wall in prone position and declined cardiac output leading to decreased $\mathrm{EtCO} 2$ value. Similar to the study conducted by Wahba $\boldsymbol{e t}$ al. ${ }^{(18)}, \mathrm{PaO} 2$ values were also observed to increase in prone position in both groups in our study as well, but higher with $\mathrm{PCV}$ group. Likewise, $\mathrm{PaCO} 2$ values in prone position also decreased in both groups. However, EtCO2 values did not change.

Pelosi et al. ${ }^{(17)}$ had reported that there were no significant differences in arterial oxygenation in addition to estimated physiological dead space ratio (VD/VT) between the supine and prone positions during VCV without PEEP. This study also showed significant increase in oxygenation with PCV group than VCV.

\section{CONCLUSION}

During general anesthesia of posterior lumbar spine surgeries in prone position it was found that both $\mathrm{P}_{\text {peak }}$ and $\mathrm{P}_{\text {plat }}$ increased after the patient was turned from supine to prone position while dynamic $\mathrm{C}_{\mathrm{dyn}}$ decreased. Comparing VCV versus PCV, with keeping of the tidal volume at $8 \mathrm{ml} / \mathrm{kg}$ and ETCO2 of $33: 35 \mathrm{mmHg}$, it was found that $\mathrm{P}_{\text {peak }}$ and $\mathrm{P}_{\text {plat }}$ decreased and the $\mathrm{C}_{\mathrm{dyn}}$ increased with the PCV group compared with VCV. As a result, oxygenation was better with the PCV group in both intraoperatively and postoperatively.

\section{REFERENCES}

1. Pumberger M, Chiu Y, Ma Y et al. (2012): National in-hospital morbidity and mortality trends after lumbar fusion surgery between 1998 and 2008. The Journal of Bone and Joint Surgery, 94(3): 359-364.

2. Davis H (1994): Increasing rates of cervical and lumbar spine surgery in the United States, 1979-1990. Spine, 19(10): 1117-23. 4.

3. Memtsoudis S, Vougioukas V, Ma Y et al. (2011): Perioperative morbidity and mortality after anterior, posterior and anterior/posterior spine fusion surgery. Spine, 36(22): 1867-5.

4. Nam Y, Yoon A, Kim Y et al. (2010): The effect on respiratory mechanics when using a Jackson surgical table in the prone position during spinal surgery. Korean Journal of Anesthesiology, 59(5): 323-328. 
5. Dharmavaram $S$, Jellish $W$, Nockels $R$ et al. (2006): Effect of prone positioning systems on hemodynamic and cardiac function during lumbar spine surgery: an echocardiographic study. Spine, 31(12): 1388-1393.

6. Choi Y, Shim J, Na S et al. (2009): Pressurecontrolled versus volume-controlled ventilation during one-lung ventilation in the prone position for robotassisted esophagectomy. Surgical Endoscopy, 23(10): 2286. 10.

7. Şenay H, Sivacı R, Kokulu S et al. (2016): The Effect of Pressure-Controlled Ventilation and VolumeControlled Ventilation in Prone Position on Pulmonary Mechanics and Inflammatory Markers. Inflammation, 39(4): 1469-1474.

8. Kim M, Kim J, Kwon S et al. (2014): Pressure controlled vs. volume controlled ventilation during prone position in high-level spinal cord injury patients: a preliminary study. Korean Journal of Anesthesiology, 67: 43-47.

9. Krayer S, Rehder K, Vettermann J et al. (1989): Position and motion of the human diaphragm during anesthesia-paralysis. Anesthesiology, 70(6): 891-898.

10. Jo Y, Kim J, Kwak Y et al. (2012): The effect of pressure-controlled ventilation on pulmonary mechanics in the prone position during posterior lumbar spine surgery: a comparison with volumecontrolled ventilation. Journal of Neurosurgical Anesthesiology, 24(1): 14-18.

11. Licker M, Diaper J, Villiger Y et al. (2009): Impact of intraoperative lung-protective interventions in patients undergoing lung cancer surgery. Critical Care, 13(2): 41-46.

12. Oeckler R, Hubmayr R (2007): Ventilator-associated lung injury: a search for better therapeutic targets. European Respiratory Journal, 30(6): 1216-1226.

13. Fernández-Pérez E, Sprung $J$, Afessa B et al. (2009): Intraoperative ventilator settings and acute lung injury after elective surgery: a nested case control study. Thorax, 64(2): 121-127.

14. Boussarsar M, Thierry G, Jaber $S$ et al. (2002): Relationship between ventilatory settings and barotrauma in the acute respiratory distress syndrome. Intensive Care Medicine, 28(4): 406-413.

15. Palmon S, Kirsch J, Depper J et al. (1998): The effect of the prone position on pulmonary mechanics is frame-dependent. Anesthesia \& Analgesia, 87(5): 1175-1180.

16. Choi Y, Shim J, Na S et al. (2009): Pressurecontrolled versus volume-controlled ventilation during one-lung ventilation in the prone position for robotassisted esophagectomy. Surgical Endoscopy, 23(10): 2286-9.

17. Pelosi P, Croci M, Calappi E et al. (1995): The prone positioning during general anesthesia minimally affects respiratory mechanics while improving functional residual capacity and increasing oxygen tension. Anesthesia \& Analgesia, 80(5): 955-960.

18. Wahba R, Tessler M, Kardash K (1998): Carbon dioxide tensions during anesthesia in the prone position. Anesthesia \& Analgesia, 86(3): 668-669. 